\title{
Anne Schwenkenbecher, Getting our Act Together: a Theory of Collective Moral Obligations, 2021 Routledge, ISBN: 9780367561123
}

\section{Olle Blomberg ${ }^{1}$}

Accepted: 28 June 2021/ Published online: 3 August 2021

(C) The Author(s), under exclusive licence to Springer Nature B.V. 2021

When it comes to problems such as global warming, world hunger or the continued spread of covid-19, it is up to $u s$ to address them. Indeed, one might think that we are morally obligated to address them, even though none of us has an ability to do it. Collective action is needed, only we can do it. At least when we consider small-scale cases, several agents can intuitively be the bearer of a moral obligation: Suppose that you and I are out hiking and encounter a man trapped under a fallen tree. He will only survive if you and I together lift the tree off him. Intuitively, we are jointly morally obligated to save him. If we don't, then we will be blameworthy for his death.

The thought that several agents can share a moral obligation may seem suspect though if one is wedded to the idea that only an agent can have an obligation, never a plurality of agents ("the agency principle"). In Getting Our Act Together, Anne Schwenkenbecher rejects this individualistic principle and argues that several individuals together have a moral obligation to $\phi$ in the sort of "joint necessity" situations just sketched, if and only if, roughly: they have a joint ability to $\phi$, and each has a reason to "we-frame" and "we-reason" to the conclusion that the best they can do (or what they must do) is to $\phi$. Each agent's reason to we-frame and we-reason should here be understood as an epistemic obligation to we-frame and we-reason (e.g. pp. 66-67, 83, 95 n. 3). This obligation, in turn, should be understood in terms of what is prospectively best to do: each ought to we-frame and we-reason in the situation if that is their morally best bet given the available evidence and their conscientious reasoning.

Schwenkenbecher's account of collective moral obligation is novel and original, but the notions of "we-framing" and "we-reasoning" that she makes use of are taken from (unorthodox) game-theoretical work by Michael Bacharach and others. For a "player" to we-frame a decision situation is to conceptualize it in terms of what is possible for the players to do together, that is, to consider options that are collectively available if they combine their actions (rather than just consider different responses to what the others are expected to do). The next step is to we-reason: to deliberate about what it is best (or morally required) for the

Olle Blomberg

olle.blomberg@gmail.com

1 Department of Philosophy, Linguistics and Theory of Science, University of Gothenburg,

Gothenburg, Sweden 
players to do together and then settle on doing one's part of the action combination that will bring about the best (or morally required) collectively available outcome.

So, in our small-scale joint rescue case, the moral obligation to save the trapped man is jointly ours because the option of saving him is only available in deliberation to $u s$ if we can be expected (given the available evidence) to each we-frame the situation and each we-reason about what we ought to do, as well as about how to do one's part of what we ought to do. Saving the trapped man is not an available option if each could only be expected to reason about what they themselves (individually) ought to do. Given that typical human beings have the capacity to we-frame and we-reason (Schwenkenbecher provides some reasons for accepting this in chapter 4), her account is arguably very appealing.

Is all this complexity and technical machinery really needed? Couldn't we just say that each individual has an obligation to do one's part if the other does theirs, or perhaps an obligation to be responsive to the other with a view to getting the trapped man released? In chapter 2, after a brief introductory chapter, Schwenkenbecher convincingly argues that such individualistic accounts (proposed by e.g. Stephanie Collins and Bob Goodin) have problems accounting for our everyday moral intuitions. For example, if we leave the man to die, then his consequent death isn't strictly speaking something that we could be blameworthy for. At most, we would be blameworthy for, say, failing to engage the other or failing to inquire whether the other was willing to do their part. This is surely an unhappy result for individualism.

By arguing that agents together can have joint abilities (chapter 3), as well as have obligations to each frame and reason practically about decision situations from a we-perspective (chapter 4), I think Schwenkenbecher at least shifts the burden of proof to the individualist. The individualist has to explain why these arguments fail to establish that a plurality of agents can share one moral obligation.

However, Schwenkenbecher's account arguably leads to the same kind of counterintuitive result that she herself takes to be a problem for individualist approaches. In chapter 5, she discusses what a collective moral obligation implies for what obligations each individual agent has. Besides the epistemic obligations to we-frame and we-reason, each has a contributory moral obligation "to see to it that the collective outcome is achieved" (p. 103). But what happens if each of us knows from the start that the other won't fulfil an obligation to we-frame or we-reason? Suppose that it is common knowledge between us that each is set on continuing hiking, unwilling to help the trapped man. In this case, it seems that neither of us would have an obligation to we-frame or we-reason (it would be pointless, as Schwenkenbecher herself suggests [pp. 87, 106]), nor an obligation to see to it that the morally required outcome is achieved. On Schwenkenbecher's account, we would thereby not have a collective moral obligation. While each would perhaps be blameworthy for not trying to engage the other in a joint rescue, it is not clear why we would be blameworthy for the trapped man's death. This is surely an unhappy result for Schwenkenbecher's collectivism.

Toward the end of the book, in chapter 6, Schwenkenbecher presents theoretical desiderata for a successful account of collective moral obligation, briefly evaluates various existing individualistic and collectivistic accounts, and presents her own account again. In the interesting seventh and final chapter, "Massively Shared Obligations", she uses her account to make sense of large-scale collective obligations to address problems such as global poverty, structural injustice or antibiotic resistance. While the weak epistemic links between agents in these cases often weaken the degree to which we are jointly able to do what seems morally required, Schwenkenbecher argues that this joint ability is nevertheless sufficient to ground 
collective moral obligations that in turn give rise to individual (pro tanto) obligations to contribute to large-scale collective action.

Those interested in the contemporary debate about collective moral obligations will find much food for thought in Getting Our Act Together. Schwenkenbecher is also a good writer: there is a nice flow to the text and it is enjoyable to read paragraph by paragraph. However, the book as a whole is unfortunately not well organised. Schwenkenbecher returns to the same questions in different chapters, and her account is presented at several places but in slightly different ways (perhaps this reflects the fact that some chapters are largely based on articles published elsewhere in self-contained form). To make the matter worse, Routledge has chosen to use endnotes rather than footnotes, and some of them contain substantive information and important clarifications. Clearly, we have a collective moral obligation to stop the use of endnotes in academic publishing! (As Daniel Dennett put it in a book review, when endnotes are abandoned, "philosophy books can aspire to be page turners in the good sense".) This obligation is only pro tanto though. If you are interested in the important topic of collective moral obligation, then don't let your contributory obligation to this particular collective moral obligation stop you from obtaining a copy of Getting Our Act Together.

Publisher's Note Springer Nature remains neutral with regard to jurisdictional claims in published maps and institutional affiliations. 